\title{
In Vitro Activation of Peroxisome Proliferator Activated Receptor $\alpha$ by Some Extracts from Food Materials
}

\author{
CHE-YI CHAO $^{1}$ AND CHING-jANG HUANG ${ }^{2}$ \\ 1. Department of Health and Nutrition Biotechnology, Asia University, Taichung, Taiwan (R.O.C.) \\ 2. Department of Biochemical Science and Technology and Institute of Micobiology and Biochemistry, \\ National Taiwan University, Taipei, Taiwan (R.O.C.)
}

(Received: October 16, 2007; Accepted: December 8, 2007)

\begin{abstract}
Peroxisome proliferator activated receptor $\alpha(\operatorname{PPAR} \alpha)$ is a ligand-dependent transcription factor that regulates the expression of genes involved in lipid metabolism and transport. Activators of PPAR $\alpha$ may be potential hypolipidemic agents, like the fibrate-type drugs. This study was therefore aimed at identifying potential hypolipidemic functional foods by screening activators of PPAR $\alpha$ from food materials. CHO-K1 cells were stably transfected with vectors (pBKCMV) carrying cDNAs of a (UAS) - $_{\text {-tk-alkaline phos- }}$ phatase reporter and a chimeric receptor Gal4-PPAR $\alpha$ LBD successively. Clones of cells responsive to Wy-14643, a known PPAR $\alpha$ activator were selected, characterized and used for testing the PPAR $\alpha$ activating potency of fractions extracted from food materials. Food materials were extracted with ethyl acetate and the extract (EAE) was cold-saponified and tested for the PPAR $\alpha$ activating ability using the selected stable transfected clone of cells. $10 \mu \mathrm{M}$ Wy-14643 (WY) was used as the positive control. Among food materials tested, EAE of bitter gourd showed the highest activity that exceeded Wy-14643, although the activity significantly decreased after saponification. The non-saponifiable fraction of onion EAE had a high maximal fold of activation equivalent to Wy-14643, while that of peanut, lychee, ricinus seed and longan showed moderate activity. The saponifiable fraction of ricinus seed, sesame and peanut also showed moderate activity. Further investigation is needed to explore the health benefit of the PPAR $\alpha$ activating food extracts found in this study.
\end{abstract}

Key words: PPAR $\alpha$, stable transfection, bitter gourd

\section{INTRODUCTION}

Peroxisome proliferator-activated receptors (PPARs) are lipid-activated transcription factors that control energy homeostasis through genomic action ${ }^{(1)}$. As other members of nuclear steroid hormone receptor superfamily, PPARs have common modulatory structures including a DNA-binding domain and a ligand-binding domain ${ }^{(2,3)}$. Upon activation by ligand binding, PPAR heterodimerizes with retinoid $X$ receptor (RXR) and promotes the transcription of its target genes through binding to a peroxisome proliferator responsive element (PPRE) ${ }^{(1,2)}$. Three subtypes of PPAR exist, namely PPAR $\alpha$ (NR1C1), PPAR $\beta / \delta$ (NR1C2) and PPAR $\gamma$ (NR1C3), which display tissue-selective expression pattern and distinct biological functions. PPAR $\alpha$ is predominantly expressed in liver, heart, kidney and skeletal muscle where it controls the fatty acid catabolism. PPAR $\alpha$ regulates the expression of genes encoding proteins that are involved in lipid

\footnotetext{
* Author for correspondence. Tel: +886-4-23323456 ext. 1859;

E-mail: cychao@asia.edu.tw
}

metabolism, fatty acid oxidation, and glucose homeostasis, thereby improving markers for atherosclerosis and insulin resistance. In addition, PPAR $\alpha$ exerts antiinflammatory effects both in the vascular wall and the liver ${ }^{(4)}$. PPAR $\gamma$ is highly expressed in brown and white adipose tissue where it triggers cellular differentiation, promotes lipid storage and modulates the action of insulin. PPAR $\beta / \delta$ is ubiquitously expressed and controls brain lipid metabolism and fatty acid-induced adipogenesis and preadipocyte proliferation ${ }^{(1,2)}$. Recent reports further demonstrated a role of PPAR in regulating glucose homeostasis, cellular differentiation and apoptosis, cancer development as well as in the control of the inflammatory response ${ }^{(4,5,6)}$.

Being the ligand / activator of PPAR $\alpha$, the fibratetype hypolipidemic drugs can induce the expression of genes that participate in lipid catabolism such as fatty acid uptake and binding, fatty acid oxidation in microsomes, peroxisomes and mitochondria and lipoprotein assembly and transport ${ }^{(3)}$. These are PPAR $\alpha$ target genes since PPRE has been identified in the promotor region 
of these genes. Using the PPAR $\alpha$ deficient mice model, the hypolipidemic action of fibrates has been found to be mediated by this receptor ${ }^{(7)}$. The results indicated that PPAR $\alpha$ ligand / activator may lower liver and/or blood lipids by up-regulating PPAR $\alpha$ target genes which in turns, enhance the oxidation of fatty acids ${ }^{(3)}$. Likewise, thiazolidinediones are PPAR $\gamma$ ligands and the antidiabetic effects exerted by this type of drugs is believed to be mediated by PPAR $\gamma^{(8,9)}$. Substantial attempts have been made currently to develop new therapeutic agents for hyperlipidemia, insulin resistance, atherosclerosis, etc. by screening agonist / antagonist of PPARs ${ }^{(1,3)}$.

In addition to common fatty acids, some compounds of diet/food origins, such as conjugated linoleic acids, ${ }^{(10)}$ have been found to be PPAR activators. The hypolipidemic effect of fish oil ${ }^{(11)}$ has been attributed, at least in part, to the activation of PPAR $\alpha$. We have shown that hydrolyzed oxidized frying oil can activate PPAR $\alpha$ and up-regulate some PPAR $\alpha$ target genes in rats ${ }^{(12)}$. It is thus desirable to identify more PPAR $\alpha$ or PPAR $\gamma$ activators from food materials from which hypolipidemic or antidiabetic functional foods may potentially be developed.

The purpose of this study is to screen PPAR $\alpha$ activators from food materials using a clone of CHO-K1 cells stably transfected with vectors (pBKCMV) carrying cDNAs of a (UAS) $)_{4}$-tk-alkaline phosphatase (ALP) reporter and a chimeric receptor Gal4-PPAR $\alpha$ ligand binding domain ${ }^{(12,13,14)}$. As PPAR activators tend to be hydrophobic, tested food materials were extracted with ethyl acetate and the PPAR $\alpha$ activating ability was compared to Wy-14643, a reference PPAR $\alpha$ ligand.

\section{MATERIALS AND METHODS}

\section{Expression and Reporter Plasmids}

The construct of chimeric receptor was pBK-CMVGal4-rPPAR $\alpha$-ligand binding domain; the reporter gene was pBK-CMV-(UAS) ${ }_{4}$-tk-ALP; antibiotic genes were $\mathrm{pSV}_{2}$-Neomycin and $\mathrm{pKSV}$-Hygromycin. These were gifts from Dr. Gustaffson, Department of Medical Nutrition, Karolinska Institute. The correct in-frame fusions were confirmed by sequencing.

\section{Food Materials for Testing}

Tested food materials were chosen from vegetables, fruits, nuts, traditional Chinese herb and microbial products. Fresh vegetables including bitter gourd (Momordica charantia L.), onion, celery, sweet potato leaves and rice seedlings and fruits including lychee (litchi, leechee or lichi, litchi sinesis Sonn) and longan (Nephelium longana Camb or Euphoria longana Lam) were purchased from local markets. Freshly roasted peanut and sesame were from a manufacturer (Ma Yu San food processing, Kaohsiung, Taiwan). Dried traditional Chinese herb including ricinus seed, lotus seed plumule (Nelumbo nucifera Gaertn) and hawthorn (Crataegi Fructus) were purchased from a local Chinese traditional medicine store. Two microbial products, Monascus anka (dried powder of Chinese red yeast rice) and Ganoderma tsugae were from Shuang Hor Enterprise Company, Tainan, Taiwan. Dried fruiting body of G. tsugae from a cultivation farm and provided by Dr. Hseu.

\section{Cell Culture and Stable Transfection}

The procedures for the establishment of cell lines stably transfected with Gal4-rPPAR $\alpha$ LBD chimeric receptor and (UAS) ${ }_{4}$ - tk -ALP reporter has been described previously ${ }^{(12,13)}$. Briefly, CHO-K1 cells (American Type Culture Collection, Rockville, MD) were grown at $37^{\circ} \mathrm{C}$ in the presence of $5 \% \mathrm{CO}_{2}$ in Ham's F-12 medium supplemented with $10 \%$ fetal bovine serum (FBS; Gibco BRL, Rockville, MD). Using lipofectamine ${ }^{\mathrm{TM}} 2000$ (Gibco BRL) according to the manufacturer's instructions, cells were first transfected with the reporter construct and $\mathrm{pSV}_{2}$-Neo. Transfected cells were selected in the presence of $0.8 \mathrm{mg} / \mathrm{mL}$ medium of G418 (neomycin). The colonies grown were pooled to form a reporter clone mix and further transfected with the chimeric receptor construct $\mathrm{pBK}-\mathrm{CMV}-\mathrm{Ga}$ 14-rPPAR $\alpha$ and pKSV-Hygro, and then selected with $0.8 \mathrm{mg} / \mathrm{mL}$ medium of hygromycin. About 150 clones were picked, expanded and tested for their responsiveness to $10 \mu \mathrm{M}$ Wy-14643 (Cayman Chemicals, Ann Arbor, MI), a known activator of rPPAR $\alpha$. Among the 10 responsive clones, clone 77 showed the maximal fold induction of the reporter gene activity, and was used for the following experiments. The expression of rPPAR $\alpha$-LBD in cells of the clone 77 was confirmed by reverse transcription-polymerase chain reaction.

\section{Activation Experiments and ALP Reporter Gene Assay}

The procedure has been described previously ${ }^{(12,14)}$. Briefly, stably transfected cells were seeded in 96-well plates and incubated with medium containing Wy-14643 or tested food extracts for $48 \mathrm{~h}$. Basal levels of expression of reporter activity were obtained with medium containing vehicles [dimethyl sulfoxide (DMSO) or ethanol] at a concentration equivalent to those used in the highest concentrations of activators. Culture supernatants were collected and assayed for ALP activity using CDPStar $^{\circledR}$ (Tropix, Applied Biosystems, Foster City, CA) as a substrate. Chemiluminescence was measured in a luminometer (Wallac 1420 Victor $^{2}$ multiple label counter; Perkin Elmer, Turku, Finland). The toxicity of the treatment on cells was checked by the 3-(4,5-dimethylthiazol2-yl) -2,5-diphenyltetrazolium bromide (MTT) (Sigma, St. Louis, MO) assay. Data are expressed as means of triplicates from one experiment and are representative of at least three experiments. Fold of activation was calculated by taking the ALP activity of the vehicle as 1 . 


\section{Extraction of Food Materials with Organic Solvent}

The extraction of tested fresh vegetables, fruits, roasted peanut and lotus seed plumule were as described ${ }^{(15,16)}$. Briefly, samples were cut into small pieces and homogenized in a Waring blender with minimal amount of doubledistilled water, and homogenates were filtered through several layers of gauze. The residues were collected and freeze-dried. The dried residues were grounded and extracted with ethyl acetate $(1: 30, \mathrm{w} / \mathrm{v})$ by stirring overnight at room temperature, followed by filtration. Dried ricinus seed, hawthorn and Monascus anka were ground and directly extracted with ethyl acetate $(1: 30, w / v)$ in the same manner. Ganoderma tusgae was ground and extracted with $95 \%$ ethanol $(1: 30, \mathrm{w} / \mathrm{v})$. Sesame was ground and extracted with $(1: 30, \mathrm{w} / \mathrm{v})$ a mixture of ethyl acetate and methanol $(1: 1, \mathrm{v} / \mathrm{v})$ in the same manner. Filtrates were evaporated in a rotary evaporator (Buchi, Germany) to eliminate the solvent. The ethyl acetate extracts (EAEs) were weighed and stored at $-20^{\circ} \mathrm{C}$. The extraction yield ( $\mathrm{g}$ / $100 \mathrm{~g}$ of the dried residue) was shown in Table 1.

\section{Hydrolysis of Food Extracts by Cold Saponification}

The EAEs were further hydrolyzed by cold saponification. After an overnight stirring with 10 volume of 3.6 $\mathrm{M} \mathrm{KOH}$ in methanol at room temperature, the saponifi-

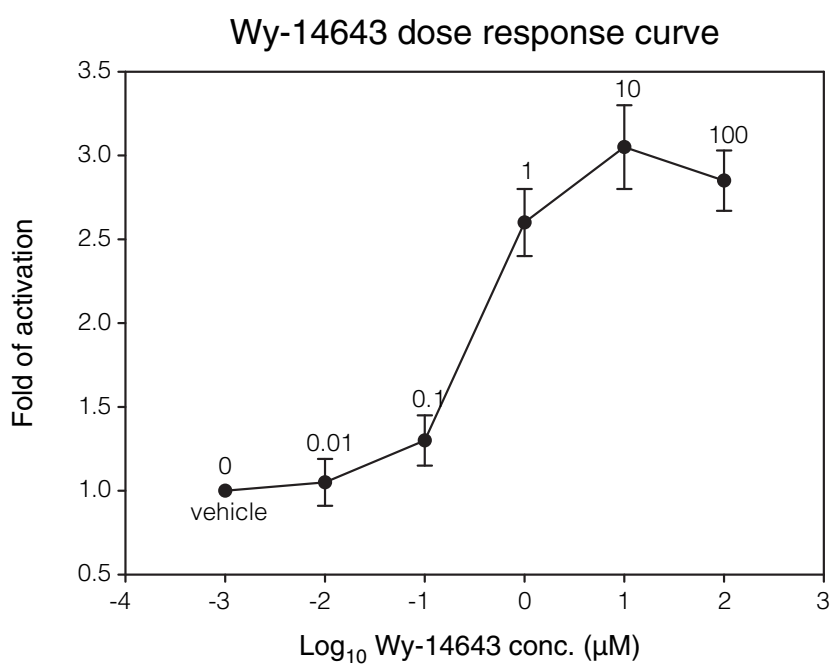

Figure 1. Dose response curve of Wy-14643 in CHO-K1 cells stably expressing the Gal4-rPPAR $\alpha$ receptor chimera and the (UAS) ${ }_{4}$-alkaline phosphatase (ALP) reporter. CHO-K1 cells were successively transfected with the reporter and receptor construct. Clones showing low background and maximum fold activation of the reporter by 10 $\mu \mathrm{M}$ Wy-14643 were expanded and treated with various concentrations of Wy-14643 for $48 \mathrm{~h}$. The cultural supernatant was analyzed for alkaline phosphatase reporter activity. The fold of activation was calculated by taking the ALP activity of the vehicle (ethanol) as 1 . The data were mean $\pm \mathrm{SD}$ of triplicates from one experiment and are representative of at least three experiments. able fractions were extracted with water, acidified with $5 \mathrm{~N} \mathrm{H}_{2} \mathrm{SO}_{4}$ and extracted with n-hexane. The nonsaponifible fractions were extracted with ethyl acetate. The saponifiable (S) and nonsaponifiable (NS) fractions were weighed after removing solvent in a rotary vacuum evaporator. Stock solutions were prepared by dissolving EAE, $S$ or NS in a minimal amount of absolute ethanol and stored at $-20^{\circ} \mathrm{C}$. The result of the saponification process was examined by thin layer chromatography (TLC) as described below and the disappearance of the triglyceride spot was confirmed. The EAE, S and NS were resolved on a normal phase TLC (Silica gel $60 \mathrm{~F}_{254}$, Merck, Darmstadt, Germany) developed using n-hexane/ ethyl acetate/ acetic acid at 80:20:2(v/v/v) as the mobile phase and visualized with iodine vapor. The developed spots were compared with standard compounds including oleic acid, linoleic acid, linolenic acid and triolein.

\section{Statistical Analysis}

Data reported are expressed as the mean \pm standard deviation of triplicate wells, and are representative of at least three separate experiments with similar results. The significance of difference between each treatment was analyzed by one-way ANOVA using SASR (SAS 8.1, Cary, N.C., USA) software.

\section{RESULTS}

\section{Dose Response Curve for Clone 77 with Wy-14643}

To establish a cell clone (CHO-K1) stably expressing the chimeric receptor in which the PPAR $\alpha$ ligand-binding domain was fused to a DNA-binding domain of the yeast transcription factor GAL4 and an ALP reporter gene fused to (UAS) 4 , about 150 transfected cell clones that grew in the presence of $0.8 \mathrm{mg} / \mathrm{mL}$ hygromycin were picked, expanded and tested for the responsiveness to Wy-14643. Ten clones were found to be responsive and further expanded. The expression of the ALP reporter gene of one of the responsive clone, clone 77, in response to Wy-14643 in a dose-dependent manner is shown in Figure 1. The cell lines obtained were used for testing the PPAR $\alpha$ activating potential of various food extracts in the following experiments. Among various batches of experiments, the fold activation of $10 \mu \mathrm{M} \mathrm{Wy}-14643$ ranged from 2 to 4 .

\section{The PPAR activation Potential of Tested Food Extracts}

The ethyl acetate extracts (EAE), as well as their saponifiable (S) or non-saponifiable (NS) fractions of tested food materials were examined for the PPAR $\alpha$ activation potential using cells of the clone 77 . The results are shown in Table 1. Among the EAEs of food materials tested, bitter gourd showed a high activity with the 
Table 1. Activation of PPAR $\alpha$ by various food extracts

\begin{tabular}{|c|c|c|c|c|}
\hline $\begin{array}{c}\text { Extract of } \\
\text { food materials }\end{array}$ & $\begin{array}{l}\text { extraction } \\
\text { yield }\end{array}$ & $\begin{array}{c}\text { concentration at maximum } \\
\text { fold activation }\end{array}$ & $\begin{array}{l}\text { maximum fold } \\
\text { of activation }\end{array}$ & $\begin{array}{l}\% \text { relative fold activation } \\
\text { to } 10 \mu \mathrm{M} \text { Wy-14643 }\end{array}$ \\
\hline $\mathrm{EAE}^{4}$ & $(\mathrm{~g} / 100 \mathrm{~g})$ & $(\mu \mathrm{g} / \mathrm{mL})$ & & $(\%)$ \\
\hline Bitter gourd & 1.86 & 100 & $7.22 * 1(2.66)^{2}$ & $375^{* 3}$ \\
\hline Lotus seed plumule & 17.25 & 500 & $1.36(2.02)$ & 35 \\
\hline Ricinus seed & 49.60 & 30 & $1.53(2.59)$ & 33 \\
\hline Sesame (EME) & 31.80 & 500 & $1.39(2.50)$ & 26 \\
\hline Onion & 1.50 & 90 & $1.36(2.50)$ & 24 \\
\hline Longan & 1.53 & 100 & $1.26(2.29)$ & 20 \\
\hline Peanut & 31.40 & 100 & $1.23(2.65)$ & 14 \\
\hline Lychee & 2.43 & 100 & $1.14(2.78)$ & 8 \\
\hline Others ${ }^{5}$ & & & $<1(2.02 \sim 3.3)$ & \\
\hline $\mathrm{S}^{4}$ & $(\mathrm{~g} / 100 \mathrm{~g})$ & $(\mu \mathrm{g} / \mathrm{mL})$ & & $(\%)$ \\
\hline Ricinus seed & 27.6 & 70 & $1.70(2.50)$ & 47 \\
\hline Sesame (EME) & 18.1 & 200 & $1.80(2.70)$ & 47 \\
\hline Peanut & 17.5 & 100 & $1.42(2.35)$ & 31 \\
\hline Onion & 0.12 & 1 & $1.42(2.73)$ & 24 \\
\hline Lotus seed plumule & 2.8 & 100 & $1.37(2.71)$ & 22 \\
\hline Bitter gourd & 0.24 & 90 & $1.26(2.72)$ & 15 \\
\hline Longan & 0.05 & 10 & $1.08(2.56)$ & 5 \\
\hline Lychee & 0.16 & 1 & $1.01(2.61)$ & $<1$ \\
\hline Others 5 & & & $<1(2.02 \sim 3.3)$ & \\
\hline $\mathrm{NS}^{4}$ & $(\mathrm{~g} / 100 \mathrm{~g})$ & $(\mu \mathrm{g} / \mathrm{mL})$ & & $(\%)$ \\
\hline Onion & 0.69 & 90 & $3.10 *(3.30)$ & 91 \\
\hline Peanut & 6.09 & 50 & $1.65(2.35)$ & 48 \\
\hline Lychee & 1.14 & 50 & $1.76(2.61)$ & 47 \\
\hline Ricinus seed & 7.35 & 50 & $1.70(2.65)$ & 42 \\
\hline Longan & 0.74 & 200 & $1.44(2.24)$ & 36 \\
\hline Bitter gourd & 1.44 & 150 & $1.57(2.72)$ & 33 \\
\hline Sesame (EME) & 7.18 & 100 & $1.41(2.78)$ & 23 \\
\hline Lotus seed plumule & 7.29 & 100 & $1.17(2.09)$ & 16 \\
\hline Others $^{5}$ & & & $<1(2.02 \sim 3.3)$ & \\
\hline
\end{tabular}

1. The fold of activation was calculated by taking the ALP activity of the vehicle (ethanol) as 1 . Data are means of triplicates from one experiment and are representative of at least three experiments. $(*) P<0.05$, significantly different from Wy- 14643 .

2. Numbers in parenthesis are the fold of activation of $10 \mu \mathrm{M}$ Wy-14643 in the same batch of experiment.

3. (Maximum fold activation of food sample-vehicle) / (fold activation of $10 \mu \mathrm{M}$ Wy-14643 in the same batch of experiment-vehicle) $\mathrm{x} 100$. (*) $P<0.05$, significantly different from $\mathrm{Wy}-14643$.

4. EAE : ethyl acetate extract; $\mathrm{S}:$ saponifiable fraction of the EAE; NS : nonsaponifiable fraction of the EAE; EME : ethyl acetate and methanol (1:1) extract.

5. Others including rice seedlings, sweet potato leaves, celery, hawthorn, Monascus anka and Ganoderma tsuga (ethanol extract). 
maximum fold of activation more than three hundred percents of Wy-14643. However, the activity significantly decreased after saponification. The maximal fold of

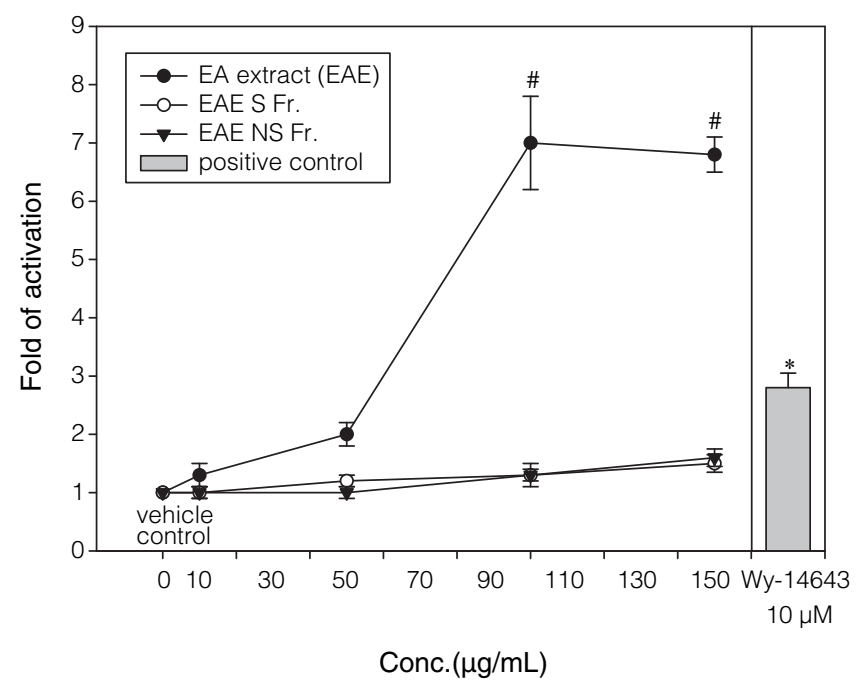

Figure 2. The transactivation of Gal4-rPPAR $\alpha$ by bitter gourd ethyl acetate extract $(-\mathbf{-})$, its saponifiable $(-\bigcirc-)$ and nonsaponifiable $(-\boldsymbol{\nabla}-)$ fractions. The data were expressed as mean $\pm \mathrm{SD}$ of triplicate wells in a representitive experiment. Data shown are representitive of at least triplicate separate experiments with similar results. Wy-14643 $(10 \mu \mathrm{M})$ was included in each experiment as a positive control. The $\mathrm{EC}_{50}$ of the EAE was $70 \mu \mathrm{g} / \mathrm{mL}$. ${ }^{*} P<0.05$ compared to vehicle control. ${ }^{\#} P<0.01$ compared to vehicle control.

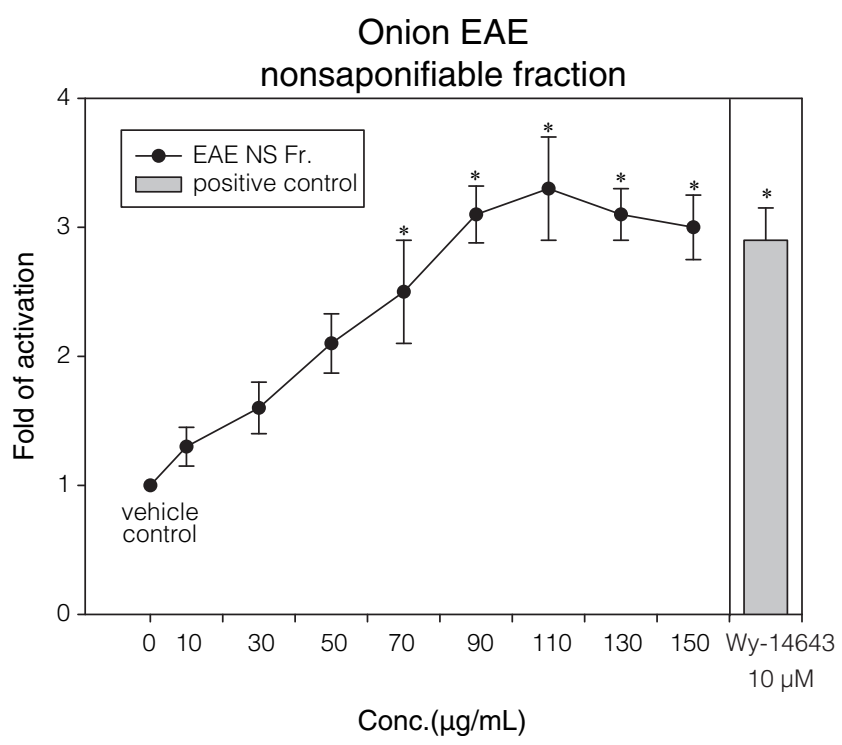

Figure 3. The transactivation of Gal4-rPPAR $\alpha$ by the nonsaponifiable fraction of onion ethyl acetate extract. The data were expressed as mean $\pm \mathrm{SD}$ of triplicate wells in a representitive experiment. Data shown are representitive of at least triplicate separate experiments with similar results. Wy-14643 $(10 \mu \mathrm{M})$ was included in each experiment as a positive control. The $\mathrm{EC}_{50}$ of the nonsaponifiable fraction of the onion EAE was $30 \mu \mathrm{g} / \mathrm{mL}$. $* P<0.05$ compared to vehicle control. activation of the remaining tested food EAEs were relatively low but increased after saponification except for lotus seed plumule. The non-saponifiable fraction of the onion EAE had a high maximal fold of activation equivalent to Wy-14643, while that of peanut, lychee, ricinus seed and longan had moderate activity (36-48\% that of Wy-14643). The saponifiable fraction of ricinus seed and sesame also showed moderate activity $(47 \%$ that of $\mathrm{Wy}-$ 14643). On the other hand, while EAE, S or NS of lotus seed plumule showed low activity, those of celery, sweet potato leaves, rice seedlings, hawthorn, Monascus anka and ethanol extract of Ganoderma tsuga did not activate PPAR $\alpha$ at all.

The dose-dependent activation of bitter gourd EAE is shown in Figure 2. The $\mathrm{EC}_{50}$ was $70 \mu \mathrm{g} / \mathrm{mL}$. Interestingly, the high activation pontency dramatically decreased after the bitter gourd EAE was saponified (Figure 2). In contrast, the EAE of onion did not show a high fold of activation, but after hydrolysis, the NS increased the ALP activity to an extent comparable to $10 \mu \mathrm{M}$ of $\mathrm{Wy}-14643$ in a dose-dependent manner (Figure 3). The $\mathrm{EC}_{50}$ was $30 \mu \mathrm{g} /$ $\mathrm{mL}$. The NS of ricinus seed EAE and $\mathrm{S}$ of sesame EME also activated PPAR $\alpha$ to a significant extent, with $\mathrm{EC}_{50}$ values of $10 \mu \mathrm{g} / \mathrm{mL}$ and $30 \mu \mathrm{g} / \mathrm{mL}$, respectively (Figure 4 and Figure 5). The fold activation of the $\mathrm{S}$ of ricinus seed EAE was comparable to that of ricinoleic acid, and the fold activation of the $\mathrm{S}$ of sesame EME were in the range of that of common fatty acids such as oleic acid and linoleic acid. All these testing were carried out in concentration

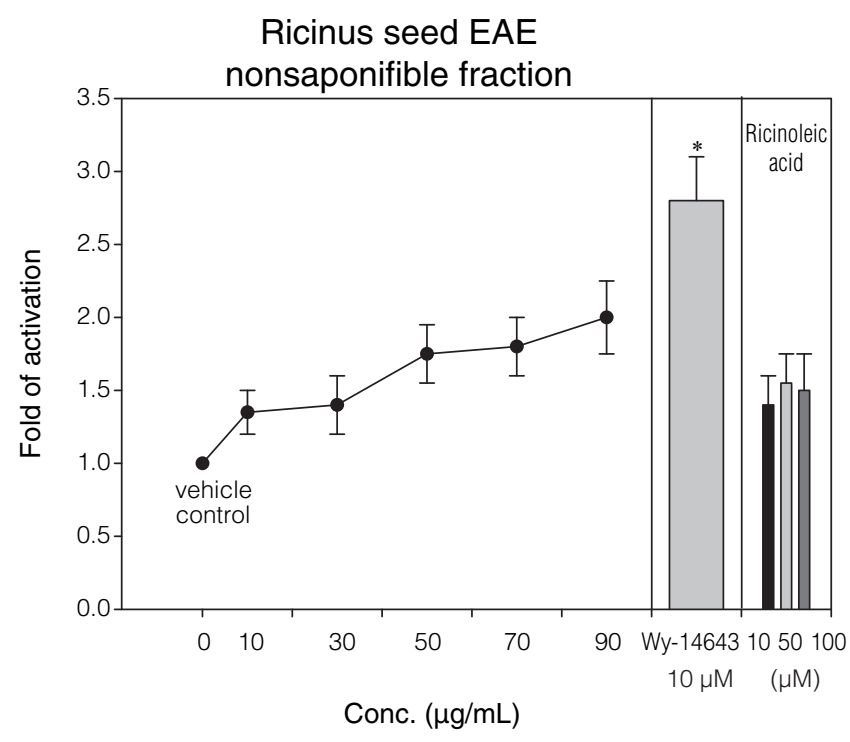

Figure 4. The transactivation of Gal4-rPPAR $\alpha$ by the nonsaponifible fraction of ricinus seed ethyl acetate extract. The data were expressed as mean $\pm \mathrm{SD}$ of triplicate wells in a representitive experiment. Data shown are representitive of at least triplicate separate experiments with similar results. Wy-14643 $(10 \mu \mathrm{M})$ was included in each experiment as a positive control. $\mathrm{The} \mathrm{EC}_{50}$ of the nonsaponifible fraction of the ricinus seed EAE was $10 \mu \mathrm{g} / \mathrm{mL} . * P<0.05$ compared to vehicle control. 


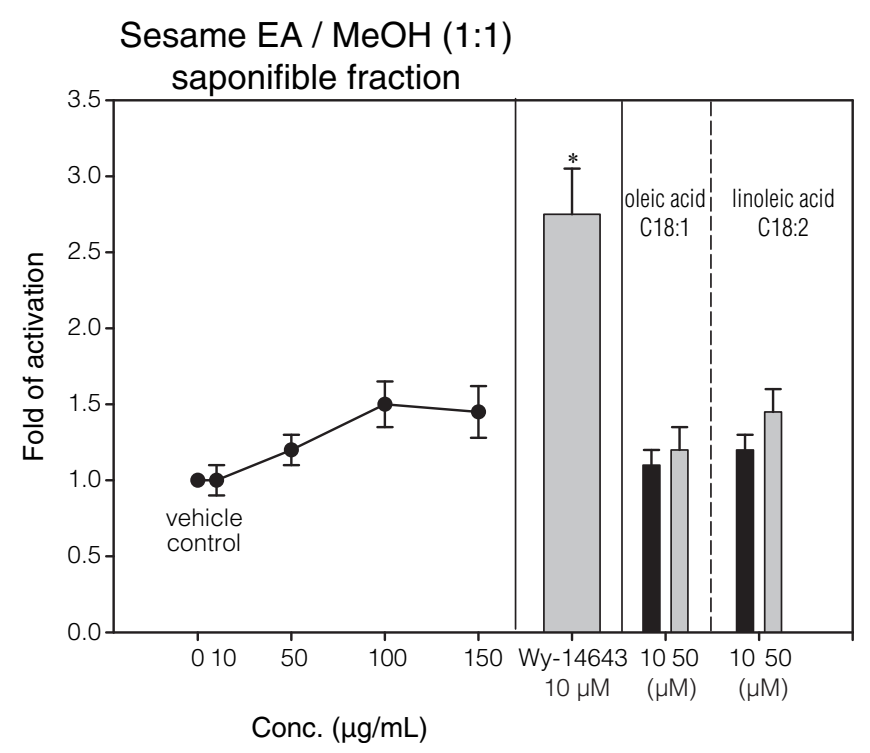

Figure 5. The transactivation of Gal4-rPPAR $\alpha$ by the saponifible fraction of sesame ethyl acetate and methanol (1:1) extract (EME). The data were expressed as mean \pm SD of triplicate wells in a representitive experiment. Data shown are representitive of at least triplicate separate experiments with similar results. Wy-14643 $(10 \mu \mathrm{M})$ was included in each experiment as a positive control. The $\mathrm{EC}_{50}$ of the saponifible fraction of the sesame EME was $30 \mu \mathrm{g} / \mathrm{mL} .{ }^{*} P<0.05$ compared to vehicle control.

ranges that did not result in significant cytotoxicity, as confirmed by the MTT assay.

\section{DISCUSSION}

Ligand binding of PPARs can induce the expression of an array of genes which in turns changes the metabolism of lipids and/or the utilization of glucose. A number of therapeutic agents, namely fibrate hypolipidemic drugs and thiazolidinedione antidiabetic drugs, are ligands of PPARs and the pharmocological effects were shown to be mediated by these nuclear receptors ${ }^{(3,8,9)}$. The transactivation assay are used to test the functional potency of a compound to activate PPAR. The assay measures the expression of a reporter gene which is driven by a promotor responsive to the specific binding of the transcription factor and in this case it is the PPAR. As PPARs are ligand dependent transcription factors, molecules bind to PPARs would activate the expression of the reporter gene. To avoid complicating the interpretation of results by endogenous receptor activation, a chimeric receptor in which the PPAR $\alpha$ ligand binding domain fused to yeast transcription factor GAL4 DNA binding domain and a reporter construct containing 4 copies of the GAL4 DNA binding site UAS driving expression of secreted placental ALP were used in this study. The approach is similar to that used for screening compounds in the pharmaceutical research and development ${ }^{(17)}$. Compared to the transient transfection approach, it is more convenient to use clone of cells stably expressing the transfected receptor and reporter for compound screening. However, it usually takes longer time to obtain such a clone and very often the clone may suffer from the instability and loss of sensitivity due to passages of cells. In this study, this can be seen from the variation in the fold of activation of the positive control, Wy-14643.

Common fatty acids are low affinity ligands of PPARs ${ }^{(18-20)}$. The fold of activation on PPARs by common fatty acids varied with the receptor and reporter constructs, cell types for transfection as well as species of PPARs originated from (mouse, rat, human or Xenopus) ${ }^{(18,21,22)}$. In this study, the fold of activation on PPARs by common fatty acids ${ }^{(18,23)}$ relative to that of $\mathrm{Wy}-14643$ is within the range of reported data.

The ethyl acetate extract of food materials was chosen for this study since the conformation of ligand binding structure of PPAR $\alpha$ is apt to hydrophobic molecules. In an attempt to include the more polar lignan compounds of sesame in the tested extract, a methanol/ethyl acetate mixture was further used to extract sesame. Sesamin, a sesame lignan, dose-dependently increased the fatty acid oxidation, activities and gene expression of hepatic fatty acid oxidation enzymes and decreased serum triglyceride in rats ${ }^{(24)}$. Authors speculated the effect may be mediated by the PPAR $\alpha$ signaling pathway. Surprisingly, sesamin and sesamol did not activate PPAR $\alpha$ in the present study, although the saponifiable fraction of sesame extract activated PPAR $\alpha$ to a level comparable to commom fatty acids. As there is not a carboxylic acid functional group in the sesamin molecule, the convincing in vivo data obtained in the rat study may be interpreted as sesamin metabolite(s) and not sesamin per se, may activate PPAR $\alpha$. CHO-K1 cells used in this study might not be able to metabolize sesamin into this active metabolite. If this is the case, the transfection experiment should be carried out in other cell types, such as liver cells. Alternately, sesamin may enhance the production of an endogenous PPAR $\alpha$ activator in vivo.

Bitter gourd is a common oriental vegetable with a number of reported health benefits. Most noteworthy is the hypoglycemic potential demonstrated in normal and diabetic rats as well as in human subjects with type II diabetes mellitus ${ }^{(25-27)}$. A diet containing 0.5 or $1 \%$ freeze-dried bitter gourd powder significantly reduced liver triglyceride and cholesterol concentration ${ }^{(28)}$. In the present study, the maximum fold activation of bitter gourd EAE was remarkably high which was more than three hundred percents relative to the fold of activation of Wy-14643. The significant hypolipidemic effect in vivo at a level of as low as $0.5 \%$ in the diet seems to coincide with the remarkably high PPAR $\alpha$ activation observed in this study. Interestingly, the PPAR $\alpha$ activation ability was diminished after the saponification of bitter gourd EAE. An anti-inflammatory potential of bitter gourd is implicated by the demonstration that extracts of bitter gourd dosedependently inhibited the LPS-induced $\mathrm{PGE}_{2}$ production 
in a macrophage cell line $\operatorname{RAW} 264.7^{(15)}$.

Our data showed that the nonsaponifiable fraction of the onion EAE has a significant PPAR $\alpha$ activation ability with the maximum fold of activation comparable to that of Wy-14643. As compounds with carboxylic acid functional groups will mainly be separated into the saponifiable fraction, constituents of the nonsaponifiable fraction theoretically do not possess any carboxylic acid functional group. It is likely that compound(s) in the nonsaponifiable fraction of onion EAE may not be the ultimate PPAR $\alpha$ ligand. Noticeably, hypolipidemic and hypoglycemic effects exerted by onion has also been demonstrated in diabetic rats ${ }^{(29)}$. It would be of interest to further test the PPAR $\gamma$ activation potential and the active component(s) in bitter gourd and onion. In addition, the in vivo regulation of the expression of PPAR target genes by the administration of bitter gourd extract or onion also worth further investigation.

In conclusion, using a clone of $\mathrm{CHO}-\mathrm{K} 1$ cells stably expressing a (UAS $)_{4}$-tk-ALP reporter and a chimeric receptor Gal4-PPAR $\alpha$ LBD, extract/fractions of food materials including: bitter gourd (375\% of WY), onion ( $91 \%$ of WY), peanut ( $48 \%$ of WY), ricinus seed $(47 \%$ of WY), sesame ( $47 \%$ of WY), lychee ( $47 \%$ of WY), longan $(36 \%$ of WY) and lotus seed plumule $(35 \%$ of WY) demonstrated significant activation on PPAR $\alpha$, whereas extract/fractions of celery, sweet potato leaves, rice seedlings, hawthorn, Monascus anka and Ganoderma tsuga did not activate PPAR $\alpha$ to a significant extent.

\section{ACKNOWLEDGEMENTS}

This study was financially supported by a grant (NSC 89-2312-B-002-013) from the National Science Council, Taiwan.

\section{REFERENCES}

1. Torra, I. P., Chinetti, G., Duval, C., Fruchart, J. C. and Staels, B. 2001. Peroxisome Proliferator-Activated Receptors: from Transcriptional Control to Clinical Practice. Curr. Opin. Lipidol. 12: 245-254.

2. Desvergne, B. and Wahli, W. 1999. Peroxisome Proliferator-Activated Receptors: Nuclear Control of Metabolism. Endocr. Rev. 20: 649-688.

3. Schoonjans, K., Staels, B. and Auwerx, J. 1996. Role of the Peroxisome Proliferator-Activated receptor (PPAR) in Mediating the Effects of Fibrates and Fatty acids on Gene Expression. J. Lipid Res. 37: 907-925.

4. Zandbergen, F. and Plutzky, J. 2007. PPAR $\alpha$ in Atherosclerosis and Inflammation. Biochim. Biophys. Acta 1771: 972-982.

5. Chinetti, G., Fruchart, J. C. and Staels, B. 2000. Peroxisome Proliferator-Activated Receptors (PPARs) : Nuclear Receptors at the Crossroads between Lipid Metabolism and Inflammation. Inflamm. Res. 49: 497-
505.

6. Kersten, S., Desvergne, B. and Wahli, W. 2000. Roles of PPARs in Health and Disease. Nature 405: 421-424.

7. Peters, J. M., Hennuyer, N., Staels, B., Fruchart, J. C., Fievet, C., Gonzalez, F. J. and Auwerx, J. 1997. Alterations in Lipoprotein Metabolism in Peroxisome Proliferator-Activated Receptor $\alpha$-Deficient Mice. J. Biol. Chem. 272: 27307-27312.

8. Bar-Tana, J. 2001. Peroxisome Proliferator-Activated Receptor Gamma (PPAR $\gamma$ ) Activation and Its Consequences in Humans. Toxicol Lett. 120: 9-19.

9. Willson, T. M., Lambert, M. H. and Kliewer, S. A. 2001. Peroxisome Proliferator-Activated Receptor $\gamma$ and Metabolic Disease. Annu. Rev. Biochem. 70: 341-367.

10. Moya-Camarena, S. Y., Vanden Heuvel, J. P., Blanchard, S. G., Leesnitzer, L. A. and Belury, M. sA. 1999. Conjugated Linoleic Acid is a Potent Naturally Occurring Ligand and Activator of PPAR $\alpha$. J. Lipid Res. 40: 1426-1433.

11. Dallongeville, J., Bauge, E., Tailleux, A., Peters, J. M., Gonzalez, F. J., Fruchart, J. C. and Staels, B. 2001. Peroxisome Proliferator-Activated Receptor Alpha is NotLimiting for the Lipoprotein-Lowering Action of Fish Oil. J. Biol. Chem. 276: 4634-4639.

12. Chao, P. M., Chao, C. Y., Lin, F. J. and Huang, C. J. 2001. Oxidized Frying Oil Up-Regulates Hepatic AcylCoA Oxidase and Cytochrome $\mathrm{P}_{450} 4 \mathrm{~A} 1$ Genes in Rats and Activates PPAR $\alpha$. J. Nutr. 131: 3166-3174.

13. Huang, C. J., Feltkamp, D., Nilsson, S. and Gustafsson, J. A. 1998. Synergistic Activation of RLD-1 by Agents Triggering PKA and PKC Dependent Signalling. Biochem. Biophys. Res. Commun. 243: 657-663

14. Chao, C. Y. and Huang, C. J. 2003. Bitter Gourd (Momordica charantia) Extract Activates Peroxisome Proliferator-Activated Receptors and Upregulates the Expression of the Acyl CoA Oxidase Gene in H4IIEC3 Hepatoma Cells. J. Biomed. Sci. 10: 782-791.

15. Huang, C. J. and Wu, M. C. 2002. Differential Effects of Foods Traditionally Regarded as "Heating" and "Cooling" on Prostaglandin $E_{2}$ Production by a Macrophage Cell Line. J. Biomed. Sci. 9: 596-606.

16. Wu, M. C. and Huang, C. J. 2001. Inhibition of Prostaglandin $\mathrm{E}_{2}$ Production of a Macrophage Cell Line by some Phytochemicals. Food Sci. Agric. Chem. 3: 59-71.

17. Henke, B. R., Blanchard, S. G., Brackeen, M. F., Brown, K. K., Cobb, J. E., Collins, J. L., Harrington, W. W., Hashim, M. A., Hull-Ryde, E. A., Kaldor, I., Kliewer, S. A., Lake, D. H., Leesnitzer, L. M., Lehmann, J. M., Lenhard, J. M., Orband-Miller, L. A., Miller, J. F., Mook, R. A., Noble, S. A., Oliver, W., Parks, D. J., Plunket, K. D., Szewczyk, J. R. and Willson, T. M. 1998. N-(2-benzoylphenyl)-L-tyrosine PPAR $\gamma$ Agonists. 1. Discovery of a Novel Series of Potent Antihyperglycemic and Antihyperlipidemic Agents. J. Med. Chem. 41: 5020-5036.

18. Forman, B. M., Chen, J. and Evans, R. M. 1997. Hypolipidemic Drugs, Polyunsaturated Fatty Acids, and 
Eicosanoids are Ligands for Peroxisome ProliferatorActivated Receptors $\alpha$ and $\delta$. Proc. Natl. Acad. Sci. U.S.A. 94: 4312-4317.

19. Lin, Q., Ruuska, S. E., Shaw, N. S., Dong, D. and Noy, N. 1999. Ligand Selectivity of the Peroxisome Proliferator-Activated Receptors $\alpha$. Biochemistry 38: 185-190.

20. Xu, H. E., Lambert, M. H., Montana, V. G., Parks, D. J., Blanchard, S. G., Brown, P. J., Sternbach, D. D., Lehmann, J. M., Wisely, G.. B., Willson, T. M., Kliewer, S. A. and Milburn, M. V. 1999. Molecular Recognition of Fatty Acids by Peroxisome Proliferator-Activated Receptors. Mol. Cell 3: 397-403.

21. Kliewer, S. A., Sundseth, S. S., Jones, S. A., Brown, P. J., Wisely, G.. B., Koble, C. S., Devchand, P., Wahli, W., Willson, T. M., Lenhard, J. M. and Lehmann, J. M. 1997. Fatty Acids and Eicosanoids Regulate Gene Expression Through Direct Interactions with Peroxisome Proliferator-Activated Receptors $\alpha$ and $\gamma$. Proc. Natl. Acad. Sci. U.S.A. 94: 4318-4323.

22. Murakami, K., Ide, T., Suzuki, M., Mochizuki, T. and Kadowaki, T. 1999. Evidence for Direct Binding of Fatty acids and Eicosanoids to Human Peroxisome Proliferator-Activated Receptors $\alpha$. Biochem. Biophys. Res. Commun. 260: 609-613.

23. Bocos, C., Gottlicher, M., Gearing, K., Banner, C., Enmark, E., Teboul, M., Crickmore, A. and Gustafsson, J. A. 1995. Fatty Acid Activation of Peroxisome Proliferator-Activated Receptor (PPAR). J. Steroid Biochem. Mol. Biol. 53: 467-473.
24. Ashakumary, L., Rouyer, I., Takahashi, Y., Ide, T., Fukuda, N., Aoyama, T., Hashimoto, T., Mizugaki, M. and Sugano, M. 1999. Sesamin, a Sesame Lignan, is a Potent Inducer of Hepatic Fatty Acid Oxidation in the Rat. Metabolism 48: 1303-1313.

25. Higashino, H., Suzuki, A., Tanaka, Y. and Pootakham, K. 1992. Hypoglycemic Effects of Siamese Momordica charantia and Phyllanthus urinaria Extracts in Streptozotocin-Induced Diabetic Rats. Nippon Yakurigaku Zasshi 100: 415-421.

26. Karunanayake, E. H., Welihinda, J., Sirimanne, S. R. and Sinnadorai, G. 1984. Oral Hypoglycemic Activity of Some Medicinal Plants of Sri Lanka. J. Ethnopharmacol. 11: 223-231.

27. Welihinda, J. and Karunanayake, E. H. 1986. Extra Pancreatic Effects of Momordica charantia in Rats. J. Ethnopharmacol. 17: 247-255.

28. Jayasooriya, A. P., Sakono, M., Yukizaki, C., Kawano, M., Yamamoto, K. and Fukuda, N. 2000. Effects of Momordica charantia Powder on Serum Glucose Levels and Various Lipid Parameters in Rats Fed with Cholesterol-Free and Cholesterol-Enriched Diets. J. Ethnopharmacol. 72: 331-336.

29. Babu, P. S. and Srinivasan, K. 1997. Influence of Dietary Capsaicin and Onion on the Metabolic Abnormalities Associated with Streptozotocin Induced Diabetes Mellitus. Mol. Cell. Biochem. 175: 49-57. 